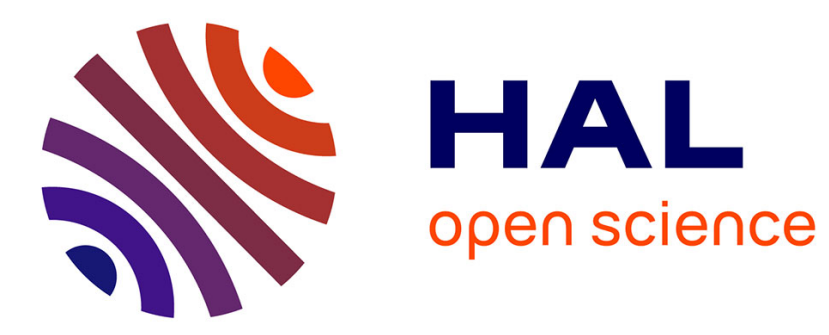

\title{
FNS or the Varseek-scale? Proposals for a valid operationalization of neophilia
}

\author{
François Lenglet
}

\section{To cite this version:}

François Lenglet. FNS or the Varseek-scale? Proposals for a valid operationalization of neophilia.

Food Quality and Preference, 2018, 66, pp.76-84. 10.1016/j.foodqual.2018.01.007 . halshs-02402036

\section{HAL Id: halshs-02402036 \\ https://shs.hal.science/halshs-02402036}

Submitted on 10 Dec 2019

HAL is a multi-disciplinary open access archive for the deposit and dissemination of scientific research documents, whether they are published or not. The documents may come from teaching and research institutions in France or abroad, or from public or private research centers.
L'archive ouverte pluridisciplinaire HAL, est destinée au dépôt et à la diffusion de documents scientifiques de niveau recherche, publiés ou non, émanant des établissements d'enseignement et de recherche français ou étrangers, des laboratoires publics ou privés. 
FNS or the Varseek-scale? Proposals for a valid operationalization of neophilia

\section{François Lenglet}

IREGE, University Savoie Mont Blanc

9 rue de l'arc-en-ciel

BP 240

74942 Annecy-le-Vieux cedex

France

Tel: +33 450092349

Fax: +33 450092337

E-mail address: francois.lenglet@univ-savoie.fr

This research did not receive any specific grant from funding agencies in the public, commercial, or not-for-profit sectors. 


\section{FNS or the Varseek-scale? Proposals for a valid operationalization of neophilia}

\section{Introduction}

Research on eating behavior has given considerable attention to the concept of neophobia. Since 2011, the two leading journals in this field (Appetite and Food Quality and Preference) have published 271 articles focused on or referring to the subject, of which one quarter (71 articles) came out last year alone ${ }^{1}$. This interest is rooted in a major specificity of food consumption, the principle of incorporation (Frazer, 1911). Foods are the only consumer product which are ingested and consequently intimately integrated into the consumer's body. Such behavior necessarily implies some risk. Our omnivore biological status, which requires the consumption of a variety of foods to meet our nutritional requirements, makes risk unavoidable. This double constraint between risk and necessity is the omnivore's paradox (Rozin, 1976), which represents a necessary compromise between two opposing adaptive tendencies, fear of change ("neophobia") and desire for novelty and variety ("neophilia").

Neophobia is often described as a reluctance to eat or an avoidance of new foods (Birch \& Fisher, 1998). As for neophilia, Steenkamp (1993) associates it with the variety-seeking tendency in the food domain, defined as "the motivation factor that aims at providing variation in stimulation through varied product consumption, irrespective of the instrumental or functional value of alternatives". Other authors retain this conceptual equivalence and consider the search for variety as the "willingness to try new foods and overall adventurousness in the diet" (Nolden \& Hayes, 2017), which is therefore hardly different from neophilia, seen as the "willingness to try new or novel foods" (Ristic, Johnson, Meiselman, Hoek, \& Bastian, 2016). Yet the variety-seeking defined as "the tendency of individuals to seek diversity in their choices of services and goods" (Kahn, 1995) can manifest itself in two distinct ways: alternation among familiar products, and desire for unfamiliar or new alternatives (McAlister \& Pessemier, 1982). This theoretical distinction is sometimes called into question because, in practice, "product familiarity is more a matter of degree than a strict dichotomy" (Baumgartner et Steenkamp, 1996: 124). However, it seems doubtful that eating an insect meatball or seaweed cheese and changing the pasta brand are all part of the same motivational factors.

Lastly, for some authors, food variety seeking and neophobia could be seen as a single continuum with approach and flight responses to novelty or dietary change at its opposing ends. Variety seeking would correspond to a favorable attitude toward risk, while neophobia would

\footnotetext{
${ }^{1}$ Search using "neophobia" as the key word on the journals' websites on March $8^{\text {th }} 2017$.
} 
reflect fear of risk (Lähteenmäki \& Arvola, 2001, pp.167-168). After twenty-five years of fruitful research in this field, the theoretical distinction between neophobia, neophilia, and variety-seeking undoubtedly deserves to be reexamined and clarified, to better justify the use of these concepts in food behavior studies. This is the first objective of the present article.

Nevertheless, two separate operationalizations have been proposed: the Food Neophobia Scale (FNS, Pliner \& Hobden, 1992), and a scale to measure the tendency to seek variety in the domain of food (Varseek-scale, Van Trijp \& Steenkamp, 1992). While the validity of the Varseek-scale has been verified, the dimensionality of FNS is still under debate since the first observations of structures with two or three dimensions (Ritchey, Frank, Hursti \& Tuorila, 2003), and the discriminant validity of the two constructs has never been established. The second objective of this article is to test the validity of these two constructs in all aspects: content validity, seen as "a priori evidence that the items are a good representation of the construct" (Rossiter, 2002; 311) and construct validity including unidimensionality, withinmethod convergent validity, reliability, discriminant validity, cross-validation, and predictive validity (Steenkamp \& Van Trijp, 1991). The final goal is to allow a rigorous choice of measurement instruments in empirical research. The study involves two samples of adult consumers, responsible for the bulk of household food purchases, in order to test trait validity $\left(\mathrm{n}_{1}=543\right)$, and predictive validity $\left(\mathrm{n}_{2}=633\right)$. The theoretical and empirical implications are discussed and research opportunities are explored.

\section{Neophilia/phobia and variety seeking: from the concept to the measure}

To understand how consumers manage the omnivore's paradox, and in line with a historically positivist approach, eating behavior researchers have developed numerous scales to measure neophobia and variety seeking (see Damsbo-Svendsen, Bom Frøst, \& Olsen, 2017 for a review). Among them, FNS and Varseek-scales are by far the most frequently used. These two scales seem to have some common theoretical foundations, but they belong to very different disciplinary, and above all, methodological approaches.

\subsection{Common theoretical foundations}

The designers of both instruments view neophobia and variety seeking as personality traits: neophobia is "a personality trait, a continuum... in terms of ... a stable propensity to approach or avoid new foods" (Pliner \& Hobden, 1992, p.107). It is thus a trait specific to the food domain which is negatively related to experience seeking, a sub-dimension of the Sensation Seeking Scale, or SSS, understood as a measure of "a need for varied, novel and complex sensations and experiences" (Zuckerman, 1979, p.10). Food variety seeking is seen as a trait specific to 
the field, a particular expression of the more general Optimum Stimulation Level (OSL) trait, which is a stable individual characteristic corresponding to an optimal level of stimulation (Van Trijp \& Steenkamp, 1992). Yet it has been shown that SSS is nothing other than one of the possible operationalizations of OSL (Wahlers, Dunn, \& Etzel, 1986; Steenkamp \& Baumgartner, 1992). Therefore, the two concepts are both personality traits specific to the food domain and derived from the same generic trait underlying a need for stimulation. Lähteenmäki \& Arvola (2001) also observe that a "low OSL is apparently one of the reasons for avoidance of new foods" and "the decision to taste or buy a new product depends on the personal optimum stimulation level" (p.168). Empirical studies have, indeed, confirmed the existence of a relationship between OSL and neophobia $(r=-0.67$ : Bäckström, Pirttilä-Backman, \& Tuorila, 2004) and between OSL and variety-seeking tendency $(r=0.354$ : Van Trijp \& Steenkamp, 1992).

Confusion between the concepts seems to increase even more if one observes that neophobia and variety-seeking share, not only the same antecedent, but also the same consequences. "Variety seeking tendency ... can be realised by either choosing a completely new food or another familiar option" (Lähteenmäki \& Arvola, 2001; p.168). Likewise, neophobia also sometimes predicts willingness to try familiar food (Tuorila, Lähteenmäki, Pohjalainen \& Lotti, 2001). In his description of the omnivore's paradox, Fischler also explicitly includes the need for novelty and variety in the concept of neophilia, and picks up on the idea of a unique tendency which manifests itself by an "oscillation between the two poles of neophobia (caution, fear of the unknown, resistance to change) and neophilia (tendency to explore, need of change, novelty, variety)" (Fischler, 1988). Conceptually, it seems important to determine whether the varietyseeking tendency should include or distinguish the desire to alternate among familiar alternatives and the desire to alternate among unfamiliar ones.

Raju (1980) initially distinguished seven types of exploratory behavior tendencies resulting from OSL, including changing brands (i.e.: "switching brands primarily for change or variety", (Raju, 1980, p. 279), and a predisposition for repetitive behavior (tendency to maintain the same type of behavioral response over time). However, these predispositions for brand change and repetitive behavior are negatively and strongly correlated, and correspond to two opposing poles of variety seeking. Therefore, they are now considered to be a single tendency (Raju \& Venkatesan, 1980). The fact that similar correlations between neophilia and variety seeking are frequently reported (e.g., r = -0.62 (Meiselman, Mastroianni, Buller, \& Edwards, 1998); -0.591 (Marshall \& Bell, 2004); -0.794 (Shenoy, 2005); and up to -0.81 (Chung et al., 2012)) may suggest that only one trend should be retained, as recommended by Raju. 
Nevertheless, strong ecological correlations do not mean theoretical confusion and it may be that neophobia/neophilia and variety-seeking are only partially overlapping concepts. Such unidimensional conceptualization seems to go against established theory of exploratory behavior that distinguishes all innovativeness and variety-seeking. Difference in the level of risk-taking between a need for novelty and a need for change would help clarify the distinction of the concepts. McAlister \& Pessemier (1982) point out that "alternating among familiar products involves very little risk" (p.314). In fact, the tendency to make exploratory purchases, and in particular the variety-seeking tendency, is more likely to be expressed in low-risk contexts and for products that are frequently purchased (Hoyer \& Ridgdway, 1984, Van Trijp, Hoyer, \& Inman, 1994). Conversely, the risk is higher in the search for novelty. Another exploratory tendency, namely risk preference, is expected to influence variety-seeking tendency (Hoyer \& Ridgway, 1984) as well as innovativeness (Rogers, 1982), but not in the same sense. The link between risk preference and innovativeness seems very strong, to the point that some authors propose that risk preference be considered as a component of innovativeness (Price \& Ridgway, 1983). Thus, the risk - taken in its situational component (perceived risk level) and individual (preference) — differs significantly between variety-seeking tendency and neophobia, and contributes to justify the conceptual distinction of concepts. Figure 1 provides a synthesis of the convergent and divergent theoretical foundations of these concepts.

Fig.1

Variety-seeking, neophobia, neophilia: conceptual distinctiveness

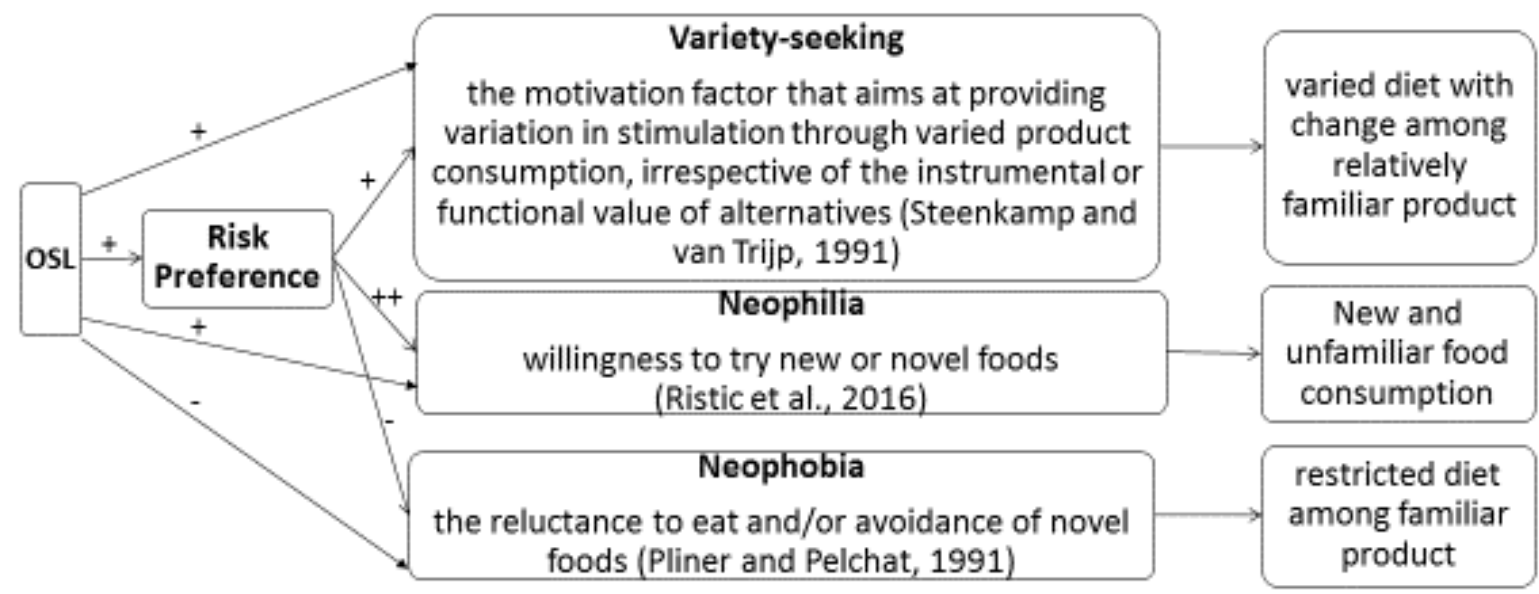


While there appears to be some arguments supporting a partial conceptual similarity between neophobia/neophilia and variety seeking tendency, the methodological foundations that led to their conventional operationalizations (FNS and Varseek-scale) are quite divergent.

\subsection{Distinct methodological substructures}

FNS was inspired by social psychology and psychopathology research (Meiselman, 2009). Neophobia is high among children between the ages of 2 and 6, and responds to a survival instinct by leading them to avoid the consumption of toxic products. However, neophobia is pathological if it does not diminish with age because it reflects an individual's failure to assume his or her omnivore status (Dovey, Staples, Gibson, \& Halford, 2008).

Pliner \& Hobden (1992) designed FNS as a one-dimensional construct with 10 items. The item generation process started with a group of 27 individuals. Out of a "large set", 18 items were pre-selected on the basis of inter-item correlations. At the end of an empirical study $(n=135)$, the authors retained the 10 most correlated items, selecting 5 positive statements and 5 negative statements in such a way as to prevent a potential effect of response pattern bias. This strategy has since been called into question due to possible problems in the emergence of the factor structure of the constructs (eg: Herche \& Engelland, 1996). The authors could not verify the one-dimensionality of their construct but later researches almost systematically led to bifactorial solutions opposing the positively and negatively coded items (eg: Ritchey et al., 2003; Paupério, Sever, et al., 2014; Fernández-Ruiz, Claret, \& Chaya, 2013). Lastly, numerous items (3, 5,8 , and 9) do not seem to really reflect neophobia (Tuorila et al., 2001; Koivisto \& Sjödén, 1996; Paupério et al., 2014). Items 8 and 9 correspond to another notion: the tendency for fussy or difficult behavior ("picky eating behavior", Demattè, Endrizzi, et al., 2013), which from a theoretical and behavioral perspective is distinct from neophobia (Dovey et al., 2008). Consequently, research studies employing this tool generally use an additive or mean score rather than a factorial score, and occasionally limit themselves to a selection of items (Bredahl, 2001; Chen, 2007).

The design of the Varseek-scale came out of consumer psychology research, and reflects a particular concern with controlling the instrument's psychometric properties. Van Trijp \& Steenkamp (1992) designed the Varseek-scale as a one-dimensional construct with 8 items. The item generation process produced 120 statements based on a literature review, two focus groups, and thirty in-depth interviews with consumers. The purification process followed the Churchill paradigm (1979): 11 items were selected on the basis of inter-item correlations and 
exploratory factor analyses. The final measurement model ( 8 items, including one with a negative statement) was validated by structural equation modeling. The scale validity was then verified on a new large sample $(\mathrm{n}=191)$.

Studies using the two scales are $\operatorname{rare}^{2}$; they do not have the same explicit comparable aims and the discriminant validity between constructs has never been established. Meiselman (2009) summarized the situation clearly: "Two different measures of variety seeking and variety avoiding appeared in 1992 (...). One might have expected variety seeking to become the more widely used scale, given its roots in more general consumer scales. But the FNS has seen much more attention and publication" (pp.347-348) ${ }^{3}$. Questions regarding the validity of these instruments may in part explain the disappointing and contradictory results often observed in the literature. According to the C-OAR-SE procedure (Rossiter, 2002), the essential type of validity is content validity. Content validity is based on a complete conceptual definition of the constructs which include an object (all foods for Variety-seeking tendency, new foods only for neophobia), an eliciting attribute (internal traits: variety-seeking tendency and neophobia), and a rater (who is an individual adult eater for the two constructs). Items should represent specific manifestations or proximal consequences of the trait, and should be written as a set of distinct mental or physical activities. Thus, in the case of FNS, only 6 out of 10 items refer explicitly to the semantic field of novelty ("new": 4 items; unknown: 2 items ("do not know")). The others are ethnic products, appreciated or considered "weird" ( 2 items), and picky eating behaviors ( 2 items). For the Varseek-scale, 6 out of 8 items refer to varying degrees of familiarity ("I am used to", "unusual", "unfamiliar", "not familiar" (2 items), "new"). The other two items concern exotic foods. Therefore, no item refers directly to "varied product consumption" (Steenkamp, 1993). This fact already has been stressed by Lähteenmäki \& Arvola (2001): "The content of the scale items resembles the FNS so that relatively many of the items are concentering, not on variety in food choice as such, but on explorative behaviour about willingness to try out unfamiliar and novel foods" (p. 166). It seems, therefore, that these scales mainly evaluate the willingness to eat new or unfamiliar foods; the distinction between new and unfamiliar may seem tenuous. Finally, other analyses are necessary to decide whether the other items belong to the domain of the construct (e.g., exotic food situations: Chen, 2007).

\footnotetext{
${ }^{2} 19$ articles, dissertations or book chapters are inventoried by Google Scholar, 7 of which in Appetite and Food Quality and Preference (websites visited on March $8^{\text {th }}$, 2017).

${ }^{3}$ A search on Google Scholar on march $8^{\text {th }}, 2017$ provided 651 references for « Food Neophobia Scale » and 71 for "Varseek-scale".
} 
An analysis of the literature provides several arguments supporting a partial conceptual similarity between food neophobia and the variety-seeking tendency: same nature (specific personality traits derived from the same generic trait), similarity between food novelty and variety, and proposals from numerous researchers to consider the concepts as two opposing poles of the omnivore's paradox. Nonetheless, difference between novelty (absolute) and unfamiliarity (relative novelty) do exist because risk perception is not the same. Empirical studies furthermore highlight recurring problems of dimensionality of FNS, a hegemonic use of this instrument, as well as strong and negative correlations with Varseek-scale. Content validity also seems questionable since the items refer to the novelty or familiarity for both scales, but by no means the variety.

The next step is to examine the construct validity of the instruments to decide whether the two operations are necessary, or whether one or the other should be chosen.

\section{Study 1: assessment of the validity of the constructs}

\subsection{Method}

After reviewing the content validity (previous section), empirical tests are now needed to assess the construct validity, including unidimensionality, within-method convergent validity, reliability, and discriminant validity (Steenkamp \& Van Trijp, 1991). The other criteria (crossvalidation, predictive validity) will be examined on a second sample in the fourth section. Unidimensionality is verified by exploratory factor analysis (EFA) and confirmatory factor analysis (CFA): according to Steenkamp \& Van Trijp (1991), the overall fit of the model provides the necessary and sufficient information to determine whether a set of items is unidimensional. In order to assess the convergent validity, it is necessary to check that the CFA provides a good fit of general adjustment of the measurement model to the data, that the factor regression coefficient of each item is significant (associated t-test higher than 1.96), and correlation of each item with the construct exceeds 0.50 . Then, the convergent validity rho is computed (Fornell \& Larcker, 1981): it provides the average variance extracted (AVE) from the construct and allows to verify the convergent validity if the latent variable shares more than $50 \%$ of its variance with its measurements. Reliability is esteemed by Cronbach's alpha (EFA) and by Jöreskog's rho (CFA). The discriminant validity is verified by examining the squares of the coefficients of correlation between factors or latent variables: if none of them is greater than the AVE, then the latent variable shares more variance with its measurement items than with the other latent concepts (Fornell \& Larcker, 1981). This discriminant validity test is a more 
stringent test than the often-used paired construct test (Farrell, 2010; Voorhees, Brady, Calantone, \& Ramirez, 2016).

The 18 items constituting the Varseek-scale and FNS were administered to a convenience sample: a group of college students solicited their parents, families, and colleagues and friends of their parents to complete an on-line questionnaire and to send it to their own acquaintances (known as the "snowball" method). The selection criteria was age (over 24 years to avoid a sample of students) and being the person in the household who shopped for food (one response per household). Consequently, $62.1 \%$ of the sample was female and the mean age was 44.2 years. Five hundred and forty-three completed questionnaires were collected, data were analyzed by exploratory and confirmatory factor analyses and subjected to reliability, convergent and discriminant validity tests. French translations of the statements were used, for which psychometric qualities had been demonstrated previously in the literature (FNS: Siegrist, Hartmann, \& Keller, 2013; Varseek-scale: author, 2002, according to the back translation method).

\subsection{FNS validity}

The first exploratory factor analysis made on the ten FNS items highlights a good representation quality (minimum communality: 0.566). An oblique rotation produces three factors with an eigenvalue superior to $1(\lambda 1=4.353 ; \lambda 2=1.106 ; \lambda 3=1.014 ; \lambda 4=0.727)$ and representing $64.73 \%$ of the scale variance. The interpretation of axes (Table 1, EFA 10 items) shows a method effect, with the negatively coded factor 1 opposing the positively coded factor 2 . Factor 3 corresponds to items 8 and 9, which reflect picky eating behavior: this already observed dimension (Dematté et al., 2013) does not belong to the construct's definition domain and must be removed to guarantee the content validity.

A new exploratory factor analysis of the eight items retained produces a solution of two correlated factors $(\mathrm{r}=-0.567 ; \mathrm{p}<0.001)$, and still corresponds to the frequently observed method effect. The quality of representation is good (minimum communality: 0.568), and the reliability of factors is satisfactory (Table 1, EFA 8 items). Factor F1 (FNS-R) returns the most information of the scale and corresponds to neophilia since it regroups the items coded negatively. This greater importance of neophilia in FNS also was observed in other studies (Tuorila et al., 2001; Paupério et al., 2014). At this stage, the unidimensionality of the construct is not established. 


\section{Table 1}

Factor analyses of the FNS scale

\begin{tabular}{|c|c|c|c|c|c|c|c|}
\hline \multirow[b]{3}{*}{ Items } & \multicolumn{7}{|c|}{ Factors loadings } \\
\hline & \multicolumn{3}{|c|}{ EFA 10 items } & \multicolumn{2}{|c|}{ EFA 8 items } & \multicolumn{2}{|c|}{ CFA 8 items } \\
\hline & F1 & $\mathrm{F} 2$ & F3 & F1 & $\mathrm{F} 2$ & F1 & $\mathrm{F} 2$ \\
\hline $\begin{array}{l}\text { FNS1: I am constantly sampling } \\
\text { new and different foods. (R) }\end{array}$ & .777 & & & .804 & & 0.639 & \\
\hline $\begin{array}{l}\text { FNS4: I like food from different } \\
\text { countries. (R) }\end{array}$ & .752 & & & .811 & & 0.720 & \\
\hline $\begin{array}{l}\text { FNS6: At dinner parties, I will try } \\
\text { a new food. (R) }\end{array}$ & .605 & & & .634 & & 0.694 & \\
\hline $\begin{array}{l}\text { FNS10: I like to try new ethnic } \\
\text { restaurants. (R) }\end{array}$ & .801 & & & .846 & & 0.763 & \\
\hline FNS2: I don't trust new foods. & & -.783 & & & .777 & & 0.762 \\
\hline $\begin{array}{l}\text { FNS3: If I don't know what is in } \\
\text { a food, I won't try it. }\end{array}$ & & -.759 & & & .809 & & 0.740 \\
\hline $\begin{array}{l}\text { FNS5: Ethnic foods look too } \\
\text { weird to eat. }\end{array}$ & & -.712 & & & .693 & & 0.737 \\
\hline $\begin{array}{l}\text { FNS7: I am afraid to eat things I } \\
\text { have never had before. }\end{array}$ & & -.724 & & & .852 & & 0.624 \\
\hline $\begin{array}{l}\text { FNS8: I am very particular about } \\
\text { the foods I will eat. }\end{array}$ & & & .726 & & & & \\
\hline $\begin{array}{l}\text { FNS9: I will eat almost anything. } \\
\text { (R) }\end{array}$ & & & .792 & & & & \\
\hline$\%$ variance extracted & 43.5 & 11.06 & 10.1 & 49.7 & 13.2 & 0.498 & 0.515 \\
\hline $\begin{array}{l}\text { Reliability (Cronbach's } \alpha \text { / } \\
\text { Joreskog's } \rho \text { ) }\end{array}$ & & & & 0.799 & 0.796 & 0.798 & 0.809 \\
\hline Correlation & & & & -0.5 & & & \\
\hline
\end{tabular}

Items for which scoring is reversed are marked $(\mathrm{R})$.

A confirmatory analysis is undertaken under Amos using the maximum likelihood method (Table 1, CFA 8 items). The one-dimensional model presents an unacceptable fit while the bifactorial solution provides a good general adjustment of the measurement model to data. The fit indices correspond to the required norms $\left(\chi^{2} / \mathrm{df}=2.732\right.$; GFI $=0.974$; AGFI $=0.951$; $\mathrm{TLI}=0.969 ; \mathrm{CFI}=0.979 ; \mathrm{RMSEA}=0.057$ ). There is an implied hierarchy among the construct validation criteria: earlier criteria (unidimensionality) should be satisfied before going to later criteria (Steenkamp \& Van Trijp, 1991: 283). Accordingly, the other validity criteria are examined by dimension or sub-construct (F1 or FNS-R: FNS items with reversed codes; F2 or FNSP: FNS items with positive codes). 
Each item factor score is significant ( $\mathrm{p}<0.001$; minimum for t-test: 13.14) and the correlation of each item with its sub-construct is above 0.50 . The within-method convergent validity (Fornell \& Larcker, 1981) is acquired for the FNS-P subscale as this latent variable shares more than $50 \%$ of its variance with its measurements $\left(\rho_{\mathrm{vc}} \mathrm{FNS}-\mathrm{P}=0.515\right)$ but this threshold is not reached by the FNS reversed-subscale $\left(\rho_{\mathrm{vc}}\right.$ FNS-R $\left.=0.498\right)$ and therefore its validity is not demonstrated. Reliabilities of the two factors are good, very close to 0.8. Although convergent validity is not achieved for FNS-R, discriminant validity is examined according to Fornell and Larcker's criteria. Here, the squared correlation between the latent variables $(0.530)$ is greater than the rhô $\hat{v c}_{\mathrm{vc}}(0.498$ and 0.515$)$ : the latent variable shares less variance with its measurement items than with the other latent factor and consequently discriminant validity is not achieved. Factor analyses (EFA and CFA) show better fits for a two-factor solution, confirming what is commonly observed in literature (eg: Ritchey et al., 2003; Fernández-Ruiz et al., 2013; Paupério et al., 2014).

\subsection{Varseek-scale validity}

EFA on the items of Varseek-scale confirms its one-dimensional structure based on the assessment of eigenvalues $(\lambda 1=3.576 ; \lambda 2=0.711)$. Nonetheless, two items had to be eliminated due to their low communality (VSK2: 0.303; VSK7: 0.353): VSK2 (While preparing foods or snacks, I like to try out new recipes) and VSK7 (I prefer to eat food products I am used to). One will observe that VSK2 puts the respondent in a situation other than tasting or eating food: it involves "preparing", an activity that may have a more social purpose and one less associated with the neophobia or neophilia characterizing the variety-seeking tendency. The case of VSK7 is again typical of reversed-coded items and their consequences on the dimensionality of constructs assessed by factor analysis. Nolden \& Hayes (2017) also retain six items. The factor restitutes $59.6 \%$ of the variance of the six items retained, and reliability is achieved (Table 2).

\section{Table 2}

Factor analysis of Varseek-scale

Loadings Loadings

$\begin{array}{lll}\text { Items } & \text { EFA CFA }\end{array}$

VSK1: When I eat out, I like to try the most unusual items, even if I $\quad 0.786 \quad 0.747$ am not sure I would like them.

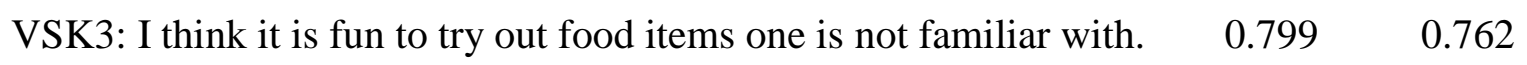


VSK4: I am eager to know what kind of foods people from other countries eat.

VSK5: I like to eat exotic foods.

VSK6: Items on the menu that I am unfamiliar with make me curious.

VSK8: I am curious about food products I am not familiar with.

0.796

0.743

\begin{tabular}{lcc}
\hline$\%$ variance extracted / $\rho \mathrm{vc}$ & 59.6 & 0.506 \\
\hline Reliability (Cronbach's $\alpha$ / Joreskog's $\rho$ ) & 0.861 & 0.863 \\
\hline
\end{tabular}

A confirmatory factor analysis provides a good general adjustment of the measurement model to data, leaving two error terms free to correlate $\left(\chi^{2} / \mathrm{df}=3.417\right.$; GFI $=0.986$; AGFI $=0.957$; $\mathrm{TLI}=0.973 ; \mathrm{CFI}=0.987$; RMSEA $=0.067)$. Each item factor score is significant $(\mathrm{p}<0.001$; minimum for t-test: 12.95) and the correlation of each item with its construct is above 0.50 . The within-method convergent validity (Fornell \& Larcker, 1981) is acquired for the Varseek-scale as this latent variable shares more than $50 \%$ of its variance with its measurements $\left(\rho_{\mathrm{vc}} \mathrm{VSK}=\right.$ 0.506). The reliability is achieved too (Joreskog's $\rho=0.863$ ).

The scales thus confirm the empirical dimensionalities observed in the literature: the Varseekscale presents good psychometric properties after the scale is lightened, while FNS does not correspond to the theoretically expected unique neophobia factor due to a methodological choice (inversion of items), which is shown to be problematic. The discriminant validity between Varseek-scale and FNS must now be examined.

\subsection{Discriminant validity}

A first confirmatory analysis is undertaken under Amos using the maximum likelihood method with the two scales as purified in the preceding section (Varseek-scale: 6 items; FNS: 8 items). It provides an acceptable general adjustment of the measurement model to data, leaving many error terms free to correlate. The fit indices correspond to the required norms $\left(\chi^{2} / \mathrm{ddl}=2,938\right.$; GFI $=0.950 ;$ AGFI $=0.920 ;$ TLI $=0.953 ; \mathrm{CFI}=0.966$; $\mathrm{RMSEA}=0.060)$. Each item factor score is significant $(\mathrm{p}<0.001)$ and the correlation of each item with its construct is above 0.50 , except FNS7 (-0.461). The convergent validity (Fornell \& Larcker, 1981) is acquired for the Varseek-scale as this latent variable shares more than $50 \%$ of its variance with its measurements $\left(\rho_{\mathrm{vc}} \mathrm{VSK}=0.512\right)$, but this is not the case for FNS $\left(\rho_{\mathrm{vc}} \mathrm{FNS}=0.384\right)$. The reliability of the two 
scales is confirmed: Joreskog's $\rho V S K=0.863$; Joreskog's $\rho F N S=0.830$. Discriminant validity is examined with the Fornell and Larcker's test: as the squared correlation between the latent variables $\left(\mathrm{r}^{2}(\mathrm{VSK}-\mathrm{FNS})=0.949^{4}\right)$ is greater than the rhô $\hat{\mathrm{vc}}_{\mathrm{cc}}$, the latent variable shares less variance with its measurement items than with the other latent concept and discriminant validity is not achieved.

However, one should keep in mind that this analysis is artificial since it does not correspond to the bi-factorial structure of FNS previously updated by EFA and confirmed by CFA (see Table 1). However, it allows the lack of construct validity (convergent and discriminant) of FNS to be established.

A second confirmatory analysis is therefore carried out in accordance with the results of the confirmatory factor analysis presented in Table 1 and 2. It incorporates three factors: Varseekscale (6 items), FNS-R subscale (4 items with reversed codes) and FNS-P subscale (4 items with positives codes). It provides a good and better general adjustment of the measurement model to data, with all of the indices corresponding to the required norms $\left(\chi^{2} / \mathrm{df}=2.479\right.$; GFI $=0.957 ; \mathrm{AGFI}=0.933 ; \mathrm{TLI}=0.964 ; \mathrm{CFI}=0.973 ; \mathrm{RMSEA}=0.052)$. The discriminant validity between Varseek-scale and FNS-R is not established since the squared correlation $\left(\mathrm{r}^{2}=0.981^{2}\right.$ $=0.962)$ is greater than the rhô ${ }_{\mathrm{vc}}$ (Table 3 ). The discriminant validity criterion is just reached for Varseek-scale and FNS-P subscale: $\mathrm{r}^{2}=-0.709^{2}=0.503$, slightly smaller than the rhô $\hat{v}_{\mathrm{vc}}(0.505$ and 0.515 ). The lack of discriminant validity between the two dimensions of FNS, highlighted previously (Table 1 ) is confirmed: $\mathrm{r}^{2}$ FNS-R - FNS-P $=0.523$. It is the same for the lack of convergent validity of FNS-R $(\rho \mathrm{vc}=0.493)$.

\section{Table 3}

Discriminant validity between Varseek-scale and the two sub-constructs of FNS

\begin{tabular}{lccc}
\hline & \multicolumn{3}{c}{ CFA standardized loadings } \\
\hline VSK1 & Varseek-scale & FNS-R & FNS-P \\
VSK3 & .740 & & \\
VSK4 & .763 & \\
VSK5 & .710 & \\
\end{tabular}

\footnotetext{
${ }^{4}$ CFA provides $r=-0.974$, while $r=-0.782$ with EFA. This correlation is very similar with what is often found in literature (see reported correlations in section 2.1.) EFA correlations are attenuated due to measurement error (Steenkamp \& Van Trijp, 1991: 294).
} 
FNS6 (R) $\quad .705$

FNS6 (R) $\quad .737$

FNS10 (R) $\quad .714$

$\begin{array}{ll}\text { FNS2 } & .755\end{array}$

$\begin{array}{ll}\text { FNS3 } & .754\end{array}$

FNS5 $\quad .719$

FNS7 .637

\begin{tabular}{lccc}
\hline$\rho_{\mathrm{vc}}$ & 0.505 & 0.493 & 0.515 \\
\hline Joreskog's $\rho$ & 0.859 & 0.795 & 0.809 \\
\hline Correlation Varseek-scale & 1 & & \\
Correlation FNS-R & 0.981 & 1 & \\
Correlation FNS-P & -0.709 & -0.723 & 1 \\
\hline
\end{tabular}

Facing such a situation, (Farrell, 2010) suggests to combine constructs into one overall measure. A factor analysis (EFA, Promax rotation) conducted on the items of the FNS-P, FNS-R subscales, and the Varseek-scale produces two factors. The interpretation of axes confirms the empirical indistinction between the Varseek-scale and FNS-R: all of the corresponding items saturate on the same first factor (Neophilia). Factor 2 corresponds to the FNS-P items (Neophobia). Inter-factor correlation is -0.663 . A confirmatory factor analysis provides a good general adjustment of the measurement model to data $\left(\chi^{2} / \mathrm{df}=2.816\right.$; GFI $=0.945$; AGFI $=0.919$; $\mathrm{TLI}=0.956$; CFI $=0.965 ; \mathrm{RMSEA}=0.058)$. Each item factor score is significant $(\mathrm{p}<0.001$; minimum for t-test: 13.64) and the correlation of each item with its construct is above 0.50 . The within-method convergent validity (Fornell \& Larcker, 1981) is acquired for the two subscales: $\rho_{\mathrm{vc}}$ VSK-FNSR $=0.511 ; \rho_{\mathrm{vc}} \mathrm{FNS}-\mathrm{P}=0.515$. The shared variance between latent variables $\left(\mathrm{r}^{2}=\right.$ $\left.-0.719^{2}=0.517\right)$ is slightly greater than the rhô $\hat{v c}_{\mathrm{vc}}$ and consequently discriminant validity is still not achieved.

In summary, none of the empirical tests carried out was able to establish clearly the discriminant validity between the items of the two scales, and the analysis of the items shows formulations centered on novelty or familiarity rather than the variety. Consequently, construct definition concerns neophobia and neophilia, which seem to form a continuum, a single construct reflected 
by Varseek-scale, FNS-R subscale, or their aggregate, the other factor (FNS-P: Neophobia) having no other justification than a method effect linked to the inversion of items. Psychometric analysis suggests that a single scale is sufficient to measure consumers' degree of neophobianeophilia.

Cross-validation and predictive validity will now be estimated_and compared on a new sample in a second study.

\section{Study 2: Cross-validation and predictive validity}

Cross-validation of the unidimensionality on new data is needed to verify that one has not "capitalized on chance" with the first sample (eg: Steenkamp \& Van Trijp, 1991). Predictive validity examines the extent to which the scale correlates with some theoretical outputs: diversity in diet for Varseek-scale, willingness to try new or unfamiliar food for FNS.

Nevertheless, examination of the content validity suggested a similitude of the items of the scales since most reflect exploratory behaviors about willingness to try out unfamiliar and novel foods and no one involves explicitly tendency to seek variety. As a result, the predictive validity test leads to review the relationship between each type of behavior (variability, novelty) and each scale (Varseek-scale, FNS).

\subsection{Method}

A new sample was constituted using the same method ("snowball") and the same criteria (age, food purchaser) than in the first study: six hundred thirty three consumers filled in the questionnaire on line, which included pre-selected items of the Varseek-scale and of FNS. The sample was $73.3 \%$ female and the mean age was 47.1 years. Cross-validation is evaluated by comparing model fits, convergent and discriminant validity between the two studies. Predictive validity was assessed by comparing the influence of the three scale (Varseek-scale, FNS-R, FNS-P) on variety behavior, familiarity, and willingness to try or eat some foods. As a dependent variable, variety behavior was measured according to the procedure proposed by Van Trijp, Lähteenmäki, \& Tuorila (1992): the subject was presented with a pre-coded list of 33 types of cheese covering the French market supply, including local and foreign varieties of cheese. Consumption was measured by the number of pre-coded alternatives that a subject reported having eaten during the previous 6 months, the possible scores thus ranging from 0 to 33 . Willingness to try unfamiliar food includes two measures: familiarity, and willingness to try. Eight food items 
were selected (Table 6). These products really exist and are marketed on the French market, and sometimes, recently. They were chosen in order to obtain very discriminating levels of familiarity. The familiarity and willingness to try each of the foods listed in the questionnaire were scales, adapted from Raudenbush \& Frank (1999), Tuorila et al. (2001), and Olabi et al. (2009). The familiarity scale comprised of four categories labeled as "I have never tasted this product $=1$ ", “ 'I have once tasted this product $=2$ ", “ 'I occasionally eat the product= 3", “ $I$ regularly eat the product $=4 "$. The 5-point willingness to try scale was anchored with only "reluctant to try/interested to try" at its ends.

Familiarity was analyzed by dividing respondents in two categories as in Tuorila et al. (2001) and Olabi et al (2009). The two categories were unfamiliar ("never tasted") and familiar ("have tasted" once or more, score 2 to 4). ANOVA were performed for each food product and for each scale or subscale (Varseek, FNS-R, FNS-P) according familiarity groups. The relationships between each scale and willingness to try each food product, and between each scale and variety behavior about cheese, were assessed by Pearson's correlation coefficients.

\subsection{Cross-validation}

The results of a new CFA with the second sample confirm the validity analyses. Here again, Varseek-scale is unidimensional, and all the indices of adjustment, reliability and convergent validity are even improving (Table 4). FNS bi-factorial solution presents an acceptable fit, although lower than Varseek-scale. As unidimensionality criteria is still not achieved for FNS, the other criteria are examined for the two sub-constructs (Table 5).

\section{Table 4}

General adjustment of the measurement models

\begin{tabular}{lcccc} 
& \multicolumn{2}{c}{ Varseek-scale } & \multicolumn{2}{c}{ Food Neophobia Scale } \\
& \multicolumn{2}{c}{ (VSK1,3,4,5,6,8) } & \multicolumn{2}{c}{ (FNS1,4,6,10; 2,3,5,7) } \\
& $\mathrm{n} 1=543$ & $\mathrm{n} 2=633$ & $\mathrm{n} 1=543$ & $\mathrm{n} 2=633$ \\
\hline$\chi^{2} / \mathrm{df}$ & 3.417 & 2.504 & 2.732 & 3.056 \\
GFI & 0.986 & 0.990 & 0.974 & 0.977 \\
AGFI & 0.957 & 0.977 & 0.951 & 0.956 \\
TLI & 0.973 & 0.990 & 0.969 & 0.971 \\
CFI & 0.987 & 0.994 & 0.979 & 0.981 \\
RMSEA & 0.067 & 0.040 & 0.057 & 0.057 \\
\hline
\end{tabular}

FNS-R subscale (neophilia) confirms its lack of convergent validity $\left(\rho_{\mathrm{vc}}<0.5\right)$. The lack of discriminant validity between the three subscales is also confirmed, as all shared variances $\left(\mathrm{r}^{2}\right)$ 
are greater than $\rho_{\mathrm{vc}}$. Varseek-scale confirms its superiority in terms of reliability. FNS-P subscale (neophobia) also has good convergent validity. However, three of its items are negatively worded: previous researches have pointed to the differential ability of respondents to deal with negatively worded items (eg: Barnette, 2000), and weakness, or even loss of predictive validity with this type of scale (eg: Lai, 1994).

\section{Table 5}

Cross-validation of Varseek-scale, FNS-R (neophilia), FNS-P (neophobia)

\begin{tabular}{lcccccc} 
& \multicolumn{2}{c}{ Varseek-scale } & \multicolumn{2}{c}{ FNS-R subscale } & \multicolumn{2}{c}{ FNS-P subscale } \\
\cline { 2 - 7 } Correlations $(\mathrm{r})$ & $\mathrm{n}_{1}=543$ & $\mathrm{n}_{2}=633$ & $\mathrm{n}_{1}=543$ & $\mathrm{n}_{2}=633$ & $\mathrm{n}_{1}=543$ & $\mathrm{n}_{2}=633$ \\
\hline Varseek-scale & 1 & 1 & & & & \\
FNS-R subscale & 0.981 & 0.958 & 1 & 1 & & \\
FNS-P subscale & -0.709 & -0.782 & -0.723 & -0.821 & 1 & 1 \\
\hline Joreskog's $\rho$ & 0.859 & 0.867 & 0.795 & 0.842 & 0.809 & 0.815 \\
\hline$\rho \mathrm{vc}$ & 0.505 & 0.522 & 0.493 & 0.499 & 0.515 & 0.526 \\
\hline
\end{tabular}

\subsection{Predictive validity}

Variety seeking behavior can be accomplished by alternating among familiar alternatives. The replication of the study by Van Trijp et al. (1992) confirms that variation reported in the use of cheese is related to Varseek-scale: $r=0.247(\mathrm{p}<0.001)$. As a comparison, these authors assessed the contribution of variety-seeking tendency through a stepwise regression analysis including sociodemographic variables and found for Varseek-scale a similar $B=0.28(p<0.01)$. In another study, Van Trijp \& Steenkamp (1992) report correlations between 0.132 and 0.370 between Varseek-scale and their four indicators of varied dietary behavior. Interestingly, FNS-P and FNS-R explains also the variety in cheese consumption in an almost equivalent way $(r=-0.270$ and 0.188 respectively; all $\mathrm{p}<0.001)$.

Variety seeking behavior can also be accomplished by choosing new or unfamiliar food products. Predictive validity implies to review how Varseek-scale and FNS-subscales are related to familiarity with food and willingness to try new food. For the sake of comparability, the presentation of the results in Table 6 is strongly based on replicated studies (Tuorila et al., 2001, Olabi et al., 2009).

\section{Table 6}


Food stimuli in the order of familiarity. ANOVA for neophobia, neophilia, variety-seeking tendency, according familiarity (not tasted vs. tried or eaten the product earlier). Correlations between FNS-P, FNS-R, VSK and willingness to try.

\begin{tabular}{|c|c|c|c|c|c|c|c|}
\hline \multirow[b]{2}{*}{ Food name } & \multirow[t]{2}{*}{$\begin{array}{c}\mathrm{N} \\
\text { (tasted) }\end{array}$} & \multicolumn{3}{|c|}{$\begin{array}{l}\text { ANOVA FNS-P, FNS-R, Varseek } \\
\mathrm{X} \text { tasted or not (F-values) }\end{array}$} & \multicolumn{3}{|c|}{$\begin{array}{l}\text { Correlation FNS-P, FNS-R, Var- } \\
\text { seek X Willingness to try }(r)\end{array}$} \\
\hline & & FNS-P & FNS-R & VSK & FNS-P & FNS-R & VSK \\
\hline Familiar foods & & & & & & & \\
\hline Vanilla ice cream & 628 & 1.981 & $8.734^{* *}$ & $11.342^{* *}$ & .003 & -.003 & -.007 \\
\hline Pineapple fruit & 627 & 1.157 & $5.191^{*}$ & $3.863^{*}$ & $-.146^{* * *}$ & $.160^{* * *}$ &, $147^{* * *}$ \\
\hline Tuna fish & 623 & 0.003 & 0.807 & 0.739 & -.008 & -.012 & -.012 \\
\hline $\begin{array}{l}\text { Strawberry yogurt } \\
\text { Unfamiliar foods }\end{array}$ & 619 & 0.006 & $7.720^{* *}$ & $5.237^{*}$ & -.023 & .02 & .028 \\
\hline Sushi & 533 & $71.570^{* * *}$ & $117.792^{* * *}$ & $98.657^{* * *}$ & $-.389^{* * *}$ & $.438^{* * *}$ & $.419^{* * *}$ \\
\hline Seaweed cheese & 43 & $6.617^{* *}$ & $3.888^{*}$ & $13.217^{* * *}$ & $-.460^{* * *}$ & $.393^{* * *}$ & $.474^{* * *}$ \\
\hline Baobab fruit juice & 25 & $8.288^{* *}$ & 2.88 & 3.077 & $-.449^{* * *}$ & $.443^{* * *}$ & $.490^{* * *}$ \\
\hline $\begin{array}{l}\text { meatballs with in- } \\
\text { sects }\end{array}$ & 17 & $6.225^{*}$ & $5.728^{*}$ & $5.771^{*}$ & $-.396^{* * *}$ & $.361^{* * *}$ & $.437^{* * *}$ \\
\hline
\end{tabular}

Neophilia measured with Varseek-scale or FNS-R is significantly higher for consumers who have tasted the familiar and also the unfamiliar food, compared to consumers who have never tasted, with the exception of baobab fruit juice and tuna fish. Neophobia measured with FNSP differs only for unfamiliar food: consumer who have tasted the new foods are less neophobic than consumer who have never tasted them. Although the methodologies differ from previous reference studies (Tuorila et al., 2001; Olabi et al., 2009: additive score on the 10 items of FNS, and categorization into three neophobic groups), the results for FNS-R and Varseek-scale point in the same direction. Thus, in terms of familiarity, Varseek-scale and FNS-R appear to have better predictive validities than FNS-P. Conversely, FNS-P would have a slight predictive advantage for unfamiliar foods.

The absolute values of the correlations between the three subscales and willingness to try new or familiar foods ranged from 0 to 0.49 . This correlations are very comparable to those obtained by Tuorila et al. (2001) (range: 0 to 0.35) and Olabi et al. (2009) (range: 0.09 to 0.57). They are higher for the unfamiliar foods (range: 0.36 to 0.49 ) compared to the familiar foods (range: 0 to 0.16). Olabi et al. (2009) and Tuorila et al. (2001) obtained a similar trend in terms of the lower magnitude of the correlations for the familiar vs. the novel foods. Varseek-scale obtains the highest correlations for the unfamiliar foods compared to FNS-P or FNS-R subscales, with the exception of Sushi. FNS-R obtains two of the highest correlations (Sushi and pineapple 
fruit), and FNS-P none. Thus, here again, in terms of willingness to try unfamiliar food, Varseek-scale appears to have better predictive validities than FNS-P, and also FNS-R.

\section{Discussion}

This research developed out of two observations: studies published on eating behavior repeatedly identify problems with the validity of FNS (e.g. Ritchey et al., 2003), and those which use the Varseek-scale and FNS observe strong, negative correlations between the two scales (eg: Chung et al., 2012). The present article examines the differences between the concepts of neophobia and the tendency to seek variety in the food domain, and analyzes the discriminant validity of the two scales associated with them. It reinforces the conceptual distinction but establishes the confusion of operationalizations. In two empirical studies, an extensive analysis of their psychometric properties established the empirical indistinction between the two constructs, and the superiority of the Varseek-scale in terms of unidimensionality, reliability, convergent and predictive validity. However, the examination of face validity strongly suggests that the Varseek-scale is an appropriate instrument for measuring neophilia, defined as the willingness to try new or unknown foods.

\subsection{Conceptual distinction}

Neophobia and variety-seeking tendency are both expressions of specific personality traits, namely food exploratory tendencies derived from a more general trait, the optimal stimulation level. They are sometimes considered to be the opposite poles of the same phenomenon (Rozin, 1976; Fischler, 1988; Steenkamp, 1993), but the level of perceived risk associated with neophilia (i.e., innovativeness in the food domain, the opposite of neophobia) and variety-seeking is not equivalent. Classical research on the exploratory tendencies therefore systematically distinguishes between the two concepts (Raju, 1980; McAlister \& Pessemier, 1982; Hoyer \& Rigdway, 1984). The desire for change among known alternatives corresponds to the search for variety as meant by McAlister and Pessemier (1982), while innovativeness reflects a desire for the unknown. Therefore, variety-seeking behavior seems motivated by boredom, while neophilia seems more motivated by curiosity. A consumer may very well change his or her product or brand choices within a familiar category of food, and at the same time refuse to buy new or unknown products. It is also possible to have a varied diet based only on alternating between relatively familiar products; this strategy then solves the omnivore's paradox while minimizing the perceived risk. As a result, neophobia defined as "the reluctance to eat and/or avoidance of novel foods" (Pliner \& Pelchat, 1991) is not the exact opposite of the tendency to seek variety 
defined as the desire for change among familiar alternatives (McAlister \& Pessemier, 1982). Likewise, the tendency to seek variety seems to be conceptually distinct from neophilia, seen as the "willingness to try new or novel foods" (Ristic et al., 2016).

The desire for change among familiar alternatives seems more specifically at the heart of the omnivore's paradox, forced to eat "varied" but not necessarily "new". This trait therefore deserves particular attention in research on nutrition and public health or in marketing for the analysis of intracategorial competition. As for neophilia, it seems to be more central to the problematic of innovation on food markets.

\subsection{Confusion of measurement scales}

The conceptual distinction justifies the existence of two different operationalizations, but this research recalls the possible lack of content validity of Varseek-scale, confirms the lack of unidimensionality of FNS, and highlights the lack of discriminant validity between FNS and the Varseek-scale: these scales therefore correspond to a single theoretical construct. The examination of the items reveals a common semantic field opposing novelty and familiarity. The legitimacy of other items is now questioned ("picky eating behavior") or discussed (exotic foods). Similarly, some items refer to an evaluative construct ("like") whereas these scales should only include a dispositional component to measure a personality trait (Meiselman et al., 1998). The items referring to a particular situation ("When I ...") also appear to be questionable since, by nature, the traits are stable over time and consistent over situations. FNS measures neophilia more than neophobia (50\% variance extracted, versus 13\%), but its convergent validity is not demonstrated. Psychometrics analyses highlight the relative superiority of Varseekscale. Nevertheless, the correlation between this scale and the variety behavior $(r=0.247)$ is much lower than its correlation with the willingness to try new foods (range: 0.39 to 0.49 ). This result suggests that Varseek-scale measures neophilia more than variety-seeking tendency. A new scale reflecting the desire to alternate among familiar foods could undoubtedly improve the empirical link between variety-seeking tendency and variation in food behavior.

Such a scale remains to be worked out. It should not refer to the semantic field of novelty, but include terms associated with varying, changing, modifying, diversifying, etc., in connection with the essential elements of the construct. This would lead to items such as "I often change food brands, even if the ones I buy satisfy me", or "Eating too often the same things seems boring to me". As it is to measure a personality trait, it should be reflexive (items reflect manifestations of the trait) and the scale should be a parsimonious and practical tool (easy to use and 
providing results not biased by method effects). Rossiter (2002) recommends no more than three to five items for a one-dimensional construct to avoid an "overmeasurement" bias.

\subsection{Limitations and future research}

This research is conducted in the French cultural and linguistic context. The recognized importance of cultural factors in food and the suspicion of a possible French paradox (Rozin, 1996) now require an intercultural validity test. The snowball method produced convenience samples, and it seems important to check the validity of the scales on more representative samples and on different populations. Nevertheless, a broader structural model to examine the nomological validity of the scales is still to be designed and tested: it should include OSL, but also risk preference, FNS and Varseek-scale, and actual or declared consumption behaviors of new and unfamiliar products. Finally, the Varseek-scale provides a valid instrument, whose items are well centered on novelty, and represents a relevant alternative to FNS, in particular for the empirical test by structural equation modeling, because of its psychometric qualities. Nevertheless, further researches would be useful to determine whether items specific to exotic foods are well within the construct domain (Chen, 2007). Future research should allow offering an alternative measure to the variety-seeking tendency, defined as alternation among familiar food products, since this construct is conceptually distinct from neophilia. Such prospects should lead to promising advances in research for a better understanding of how consumers manage to reconcile the double constraint of the omnivore's paradox.

\section{Conclusion}

This research questions the theoretical positioning of neophobia and the variety-seeking tendency: these exploratory tendencies are not the two opposite poles of a same continuum, but rather two distinct constructs. They do not involve the same risk to the consumer, and novelty and variety do not have the same impact on consumers' food choices. Consequently, their operationalization (Varseek-scale and FNS) are subjected to comparative validity analyzes. FNS content validity seems good, but construct validity is not established, while Varseek-scale construct validity is confirmed, but content validity is questioned since the items are rooted in novelty or unfamiliarity, not in variety. Moreover, the discriminant validity between the two scales is not established. The extensive validity analyzes conducted in this research suggest that Varseek-scale should be preferred as a valid measure of neophilia. Its psychometric qualities should encourage the use of correlation, regression, and structural equation modeling, in place of recurrent practices of dichotomization, as there is now enough evidence in the literature to banish 
this statistical approach (Fitzsimons, 2008). Implications of this research concerns also the need for another scale devoted to variety-seeking tendency measurement, when familiar food are specifically involved.

\section{References}

Bäckström, A., Pirttilä-Backman, A. M., \& Tuorila, H. (2004). Willingness to try new foods as predicted by social representations and attitude and trait scales. Appetite, 43(1), 75-83.

Barnette, J. J. (2000). Effects of stem and Likert response option reversals on survey internal consistency: If you feel the need, there is a better alternative to using those negatively worded stems. Educational and Psychological Measurement, 60(3), 361-370.

Baumgartner, H., \& Steenkamp, J. B. E. (1996). Exploratory consumer buying behavior: Conceptualization and measurement. International journal of Research in marketing, 13(2), 121137.

Birch, L.L., \& Fisher, J.O. (1998). Development of eating behaviours among children \& adolescents, Pediatrics, 101, 539-549.

Bredahl, L. (2001). Determinants of consumer attitudes and purchase intentions with regard to genetically modified food-results of a cross-national survey, Journal of consumer policy, 24(1), 23-61.

Chen, M. F. (2007). Consumer attitudes and purchase intentions in relation to organic foods in Taiwan: Moderating effects of food-related personality traits, Food Quality and Preference, 18(7), 1008-1021.

Chung, L., Chung, S.J., Kim, J.Y., Kim, K.O., O’Mahony, M., Vickers, Z., ... \& Kim, H.R. (2012). Comparing the liking for Korean style salad dressings and beverages between US and Korean consumers: Effects of sensory and non-sensory factors, Food Quality and Preference, 26(1), 105-118.

Churchill, G.A (1979). A paradigm for developing better measures of marketing constructs, Journal of marketing research, 16, 64-73.

Damsbo-Svendsen, M., Frøst, M. B., \& Olsen, A. (2017). A review of instruments developed to measure food neophobia. Appetite, 113, 358-367.

Demattè, M.L., Endrizzi, I., Biasioli, F., Corollaro, M.L., Pojer, N., Zampini, M., ... \& Gasperi, F. (2013). Food neophobia and its relation with olfactory ability in common odour identification, Appetite, 68, 112-117.

Dovey, T.M., Staples, P.A., Gibson, E.L., \& Halford, J.C. (2008). Food neophobia and 'picky/fussy'eating in children: A review, Appetite, 50(2), 181-193. 
Farrell, A. M. (2010). Insufficient discriminant validity: A comment on Bove, Pervan, Beatty, and Shiu (2009). Journal of Business Research, 63(3), 324-327.

Fernández-Ruiz, V., Claret, A. \& Chaya, C. (2013). Testing a Spanish-version of the food neophobia scale, Food Quality and Preference, 28(1), 222-225.

Fischler, C. (1988). Food, self and identity, Social Science Information, 27, 275-292.

Fitzsimons, G.J. (2008). “Death to Dichotomizing”, Journal of Consumer Research, 35(1), 58.

Fornell, C., \& Larcker, D.F. (1981). Evaluating structural equation models with unobservable variables and measurement error, Journal of Marketing Research, 18, 39-50.

Frazer, J.G. (1981). Le rameau d'or, Paris, Robert Laffont, Traduit de l'édition anglaise (1911). Herche, J., \& Engelland, B. (1996). Reversed-polarity items and scale unidimensionality. Journal of the Academy of Marketing Science, 24(4), 366-374.

Hoyer, W. D., \& Ridgway, N. M. (1984). Variety seeking as an explanation for exploratory purchase behavior: A theoretical model. NA-Advances in Consumer Research Volume 11.

Journal of Marketing Research, 16(1), 64-73.

Kahn, B. E. (1995). Consumer variety-seeking among goods and services: An integrative review. Journal of Retailing and Consumer Services, 2(3), 139-148.

Koivisto, U. K., \& Sjödén, P. O. (1996). Food and general neophobia in Swedish families: Parent-child comparisons and relationships with serving specific foods. Appetite, 26(2), 107118.

Lähteenmäki, L., \& Arvola, A. (2001). Food neophobia and variety seeking — consumer fear or demand for new food products, in Frewer, L. J., Risvik, E., \& Schifferstein, H. (Eds.) Food, People and Society (pp. 161-175). Heidelberg, Springer Berlin.

Lai, J. C. (1994). Differential predictive power of the positively versus the negatively worded items of the Life Orientation Test. Psychological Reports, 75(3_suppl), 1507-1515.

McAlister, L., \& Pessemier, E. (1982). Variety seeking behavior: An interdisciplinary review, Journal of Consumer research, 9(3), 311-322.

Meiselman, H.L. (2009). Recent Developments in Consumer Research of Food, in H.R. Moskowitz, I.S. Saguy et T. Strauss (coord.), An Integrated Approach to New Food Product Development, CRC Press, 345-368.

Meiselman, H.L., Mastroianni, G., Buller, M. \& Edwards, J. (1998). Longitudinal measurement of three eating behavior scales during a period of change, Food quality and preference, 10(1), $1-8$. 
Nolden, A. A., \& Hayes, J. E. (2017). Perceptual and affective responses to sampled capsaicin differ by reported intake. Food Quality and Preference, 55, 26-34.

Olabi, A., Najm, N. E. O., Baghdadi, O. K., \& Morton, J. M. (2009). Food neophobia levels of Lebanese and American college students. Food Quality and Preference, 20(5), 353-362.

Paupério, A., Sever, M., Lopes, C., Moreira, P., Cooke, L., \& Oliveira, A. (2014). Could the Food Neophobia Scale be adapted to pregnant women? A confirmatory factor analysis in a Portuguese sample, Appetite, 75, 110-116.

Pliner, P., \& Hobden, K. (1992). Development of a scale to measure the trait of food neophobia in humans, Appetite, 19(2), 105-120.

Pliner, P., \& Pelchat, M. L. (1991). Neophobia in humans and the special status of foods of animal origin. Appetite, 16(3), 205-218.

Price, L. L., \& Ridgway, N. M. (1983). Development of a scale to measure use innovativeness. NA-Advances in Consumer Research Volume 10.

Raju, P. S., \& Venkatesan, M. (1980). Exploratory behavior in the consumer context: a state of the art review. ACR North American Advances.

Raju, P.S. (1980). Optimal Stimulation Level: Its relationship to Personality, Demographics and Exploratory Behavior. Journal of Consumer Research, 7(3), 272-282.

Raudenbush, B., \& Frank, R. A. (1999). Assessing food neophobia: The role of stimulus familiarity. Appetite, 32(2), 261-271.

Ristic, R., Johnson, T. E., Meiselman, H. L., Hoek, A. C., \& Bastian, S. E. (2016). Towards development of a Wine Neophobia Scale (WNS): Measuring consumer wine neophobia using an adaptation of The Food Neophobia Scale (FNS). Food Quality and Preference, 49, 161-167. Ritchey P.N., Frank R.A., Hursti U.K., \& Tuorila, H. (2003). Validation and cross-national comparison of the food neophobia scale (FNS) using confirmatory factor analysis. Appetite, 40(2), 163-173.

Rogers E.M., (1982), Diffusion of Innovations, $3^{\text {rd }}$ ed., Macmillan

Rossiter, J.R. (2002). The C-OAR-SE Procedure for Scale Development in Marketing. International Journal of Research in Marketing, 19, 305-335.

Rozin, P. (1976). The selection of foods by rats, humans, and other animals. Advances in the Study of Behavior, 6, 21-76.

Shenoy, S. (2005). Food tourism and the culinary tourist. PhD, Graduate school of Clemson University.

Siegrist, M., Hartmann, C., \& Keller, C. (2013). Antecedents of food neophobia and its association with eating behavior and food choices. Food Quality and Preference, 30(2), 293-298. 
Steenkamp, J. B. E., \& Van Trijp, H. C. (1991). The use of LISREL in validating marketing constructs. International Journal of Research in marketing, 8(4), 283-299.

Steenkamp, J-B. E. M. (1993). Food Consumption Behavior. European Advances in Consumer Research, 1, 401-409.

Steenkamp, J-B. E. M., \& Baumgartner, H. (1992). The role of optimum stimulation level in exploratory consumer behavior. Journal of Consumer Research, 19(3), 434-448.

Tuorila, H., Lähteenmäki, L., Pohjalainen, L., \& Lotti, L. (2001). Food neophobia among the Finns and related responses to familiar and unfamiliar foods. Food Quality and Preference, 12(1), 29-37.

Van Trijp, H. C. M., \& Steenkamp, J-B. E. M. (1992). Consumers' variety seeking tendency with respect to foods: measurement and managerial implications. European Review of Agricultural Economics, 19(2), 181-195.

Van Trijp, H. C. M., Hoyer, W. D., \& Inman, J. J. (1994). Why switch? Variety seeking behavior as an individual x product interaction. Advances for Consumer Research, Volume 22, Boston, Massachusetts

Van Trijp, H. C., Lähteenmäki, L., \& Tuorila, H. (1992). Variety seeking in the consumption of spread and cheese. Appetite, 18(2), 155-164.

Voorhees, C. M., Brady, M. K., Calantone, R., \& Ramirez, E. (2016). Discriminant validity testing in marketing: an analysis, causes for concern, and proposed remedies. Journal of the Academy of Marketing Science, 44(1), 119-134.

Wahlers, R. G., Dunn, M. G., \& Etzel, M. J. (1986). The congruence of alternative OSL measures with consumer exploratory behavior tendencies. Advances in consumer research, 13(1), 398-402.

Zuckerman M. (1979). Sensation Seeking: beyond the optimal level of arousal. Hillsdale, NJ, Lawrence Erlbaum. 